\title{
Vigilância sanitária e pesquisa-ação: a emergência de novas tecnologias no processo de trabalho e em pesquisa
}

\author{
Health surveillance and action research: the emergence of new \\ technologies in the work process and research
}

\author{
Daniella Guimarães \\ Araújo \\ Agência Nacional de Vigi- \\ lância Sanitária (ANVISA), \\ Brasília, DF, Brasil \\ E-mail: daniella.araujo@ \\ anvisa.gov. br \\ Marilene Barros Melo \\ Escola de Saúde Pública de \\ Minas Gerais (ESPMG), Belo \\ Horizonte, MG, Brasil \\ Luiz Carlos Brant \\ Universidade Federal de \\ Minas Gerais (UFMG), Belo \\ Horizonte, MG, Brasil \\ Francisco Cecílio Viana \\ Centro Mineiro de Estudos \\ Epidemiológicos e Ambien- \\ tais (CEMEA), Belo Hori- \\ zonte, MG, Brasil \\ Max André dos Santos \\ Secretaria Municipal de \\ Saúde de Belo Horizonte \\ (SMS/MG), Belo Horizonte, \\ MG, Brasil
}

\begin{abstract}
RESUMO
Este artigo resulta da pesquisa-ação "A experiência de implantação do Plano diretor de Vigilância Sanitária - PDVISA - em um contexto municipal". Tem como obj etivo analisar as quatro tecnologias que emergiram a partir dessa investigação, não usuais em pesquisa ou no processo de trabalho. Foram caracterizadas como tais devido a terem assumido a posição de produtos da pesquisa e de instrumentos para a coleta de informações, contribuindo para a consolidação do estudo. A primeira, denominada de Histórias da VISA real, introduziu a técnica de contar histórias baseada nas experiências vividas pelos trabalhadores. A segunda, o seminário Vigilância Sanitária, Integralidade e Mobilização Social, favoreceu a inclusão da comunidade e setor regulado em discussões sobre a integralidade e mobilização social. A terceira, o projeto VISAMAIS, buscou ações educacionais com setores da comunidade. E a quarta foi a recepção da Mostra cultural VISA e cidadania, do CECOVISA/ FIOCRUZ, como uma estratégia de aproximar a comunidade das ações em VISA. Essas tecnologias influíram favoravelmente na transformação da realidade em VISA ao se firmarem na fundamentalidade da escuta das múltiplas vozes e na responsabilização dos diversos suj eitos que constituem as práticas em Vigilância Sanitária.
\end{abstract}

PALAVRAS-CHAVE: Pesquisa-ação; Vigilância Sanitária; Mobilização Social

\section{ABSTRACT}

This article results from the action research "The implantation experience of the Sanitary Surveillance Forward Plan - in a municipal context". The objective is to analyze the four technologies that have emerged from this inquiry, not usual in researches or in the process of work. They have been characterized as such, as they have assumed the position of research products, and instruments for information collection, contributing for the consolidation of the study. The first, called Stories from 'Real VISA', introduced the story telling technique based on experiences lived by the workers. The second, the seminary Sanitary Surveillance, Integrality and Social Mobilization, favored the inclusion of the community and the regulated sector in quarrels on the completeness and social mobilization. The third, the VISAMAIS project, aimed educational actions with sectors of the community, and the forth was the reception of the cultural exposition Sanitary Surveillance and Citizenship from CECOVISA/ FIOCRUZ, as an approaching strategy involving the community and the actions in Sanitary Surveillance. These technologies have favorably influenced the Sanitary Surveillance's reality transformation, sign on the fundamentality of listening to multiple voices and accountability of the various subjects that constitute the health surveillance practice.
\end{abstract}

KEYWORDS: Action Research; Sanitary Surveillance; Social Mobilization 


\section{Introdução}

A reflexão sobre o processo de trabalho em Vigilância Sanitária - VISA e o consequente reordenamento de suas ações no município exige estratégias de enfrentamento dos problemas e necessidades contemporâneos de saúde. Trata-se da sobrevivência da própria Vigilância Sanitária como ação competente em saúde.

Propostas de reorganização em diversos fóruns, apresentação científica em simpósios e congressos, e tentativas isoladas de municípios brasileiros apontam para a necessidade de mudança no modelo de atenção em VISA. Transformações que, segundo Costa $^{1}$ e Lucchese ${ }^{2}$, incorporem outras tecnologias vindas do campo da sociologia, da comunicação e da psicologia social, para a construção de uma "inteligência sanitária" articulada com as necessidades de saúde da população e com as demandas e questões do "mercado".

No município de Sete Lagoas - MG, a VISA situava-se em uma condição de exclusão das demais áreas do Sistema Único de Saúde - SUS, de fragmentação de suas ações e descontextualização dos problemas sanitários, e reunia um conjunto de trabalhadores insatisfeitos. Além disso, havia pouca visibilidade e credibilidade das ações da VISA entre os demais setores da Secretaria Municipal de Saúde - SMS, outros órgãos públicos e, especialmente, o setor regulado e a população.

Diante desse contexto, a Escola de Saúde Pública de Minas Gerais - ESP-MG e a Secretaria Municipal de Saúde de Sete Lagoas, com apoio da Agência Nacional de Vigilância Sanitária - ANVISA, optou por realizar uma pesquisa-ação, na qual se pretendeu compreender a prática em vigilância, desenvolver seu conhecimento e transformá-la. Essa investigação durou 14 meses durante os anos de 2008 e 2009, e teve por objetivo identificar os fatores restritivos e propulsores ao Plano Diretor de Vigilância Sanitária - PDVISA ${ }^{3}$. Esse plano foi aprovado pela Portaria GM/ MS 1052 em 20074, como uma estratégia para consolidação e fortalecimento do Sistema Nacional de Visa.

0 presente artigo tem como obj etivo apresentar e analisar as quatro tecnologias utilizadas para identificar os fatores restritivos e propulsores na implementação do Plano Diretor de Vigilância Sanitária - PDVISA. Essas tecnologias, com base em Merhy $^{5}$, caracterizam-se como tecnologias leves, organizadas de maneira a dar voz e estabelecer uma relação de confiança mútua e de comprometimento entre os diversos suj eitos envolvidos. Configuram-se, então, como estratégias de garantir condições favoráveis à saúde e capturar o "não dito" da dinâmica do processo de trabalho em VISA, de forma que a vigilância sanitária passe a ocupar um lugar concreto, e não apenas 0 imaginário da sociedade.

\section{Procedimentos Metodológicos}

Adotou-se a modalidade de pesquisa-ação para o desenvolvimento da pesquisa. A opção por esse método se baseou em autores como Michel J ean- Thiollent ${ }^{6,7}$, Richardson ${ }^{8}$, Fran$\mathrm{CO}^{9} \mathrm{e}$ na possibilidade que este apresentava para um melhor conhecimento do contexto da VISA e de transformação dessa realidade. Utilizaram-se, assim, estratégias de problematização da ação coletiva em VISA com a totalidade dos sujeitos investigados, tais como: interações dialógicas, formação de acordos/negociações, superação de assimetrias de saber e poder, integração de processos de reflexão/ pesquisa e formação, e o levantamento das necessidades emergentes do processo de trabalho.

Considerando o processo de trabalho tradicional em VISA no município investigado, no qual as ações eram centradas em inspeções e verticalização de demandas, e a sua missão de preservar o interesse público por meio do controle sanitário, de modo que esse também se situe na perspectiva de ações educativas e construtoras de cidadania, deparou-se com a carência de instrumentos de pesquisa que fortalecessem esse propósito. Para isso, foram realizadas práticas coletivas fundamentadas no referencial da pesquisa e na sua perspectiva de consolidar a participação de toda a equipe. Dessas práticas foram constituídas algumas tecnologias que emergiram do processo vivido pelo conjunto de trabalhadores de um serviço de VISA em um município de médio porte, considerando um ano eleitoral e suas implicações.

Sob essa perspectiva e fundamentados na concepção de tecnologia constituída por Merhy ${ }^{5}$, que classifica as tecnologias envolvidas no trabalho em saúde como: leve; leve-dura e dura. As tecnologias leves caracterizam-se como as de relações do tipo produção de vínculo, autonomização, acolhimento, gestão como uma forma de governar os processos de trabalho. As leve-duras situam-se como saberes bem estruturados que operam no processo de trabalho em saúde, como a clínica médica, a psicanalítica, a epidemiologia, o taylorismo. E a dura relaciona-se aos equipamentos tecnológicos do tipo máquinas, normas, estruturas organizacionais.

As tecnologias constituídas foram: as oficinas de contar histórias - "Histórias da VISA real"; o Seminário: Vigilância Sanitária, integralidade e mobilização social; o Projeto VISAMAIS; e a recepção da Mostra Cultural VISA e Cidadania do CECOVISA/ FIOCRUZ. Pautaram-se na acepção de tecnologia leve em saúde de Merhy ${ }^{5}$ e em um misto de não conformidades vivenciadas no cotidiano dos trabalhadores quando os seus ol hares confrontaram com situações idealizadas. Brotaram da escassez de vozes anteriormente dada àquele coletivo, de situações carregadas de surpresas, incompreensões, desânimos, ausências. E de um esforço para tornar atitude palavras que, usualmente, a saúde coletiva difunde largamente: cidadania, empoderamento, autonomia, diálogo, mobilização social. Formalizando, assim, o que Carlos Matus ${ }^{10}$ denomina de Ação Humana, sintetizada como ações sustentadas por uma intencionalidade e reflexividade, diante de situações de cooperação e conflito. Nessa perspectiva, os suj eitos da pesquisa, através de suas práticas individuais e coletivas, foram construindo análises e alternativas de enfrentamento, possibilitando assim o avanço dessas intenções. 


\section{Era uma vez uma oficina de contar histórias.. .}

A oficina de relatos de histórias "Histórias da VISA Real" constituiu-se em um instrumento para viabilizar a discussão sobre os processos dialógicos no campo da VISA. A comunicação e educação em VISA possuem vários desafios metodológicos a serem enfrentados. Entre eles, destacamos a construção participativa de diversos atores que compõem as esferas municipais, estaduais e federais na perspectiva de aprendizagem e transformação dos contextos por meio dos conteúdos narrativos de seus trabalhadores. E, a partir desses, buscar a superação da assimetria na comunicação e subsídios pedagógicos para a qualificação de trabalhadores.

A comunicação no processo de trabalho em VISA deve ser pensada tanto nos espaços de interação de seus técnicos, no Sistema Nacional de Vigilância Sanitária como um todo e nas instâncias que favorecem a interação destes com públicos diversificados. Com vistas a transformar a prática predominante nas instituições de saúde para a perspectiva de Bakhtin ${ }^{11}$ para quem a natureza da língua é o diálogo, é a interação verbal.

$\mathrm{Na}$ visão de Oliveira ${ }^{12}$, o ato de ouvir e contar histórias, geralmente, é norteado por um "fio condutor, uma linha temporal e evolutiva", reproduzindo a vida. Foi nessa expectativa que se adotou essa tecnologia, originária dos casos contados pela equipe de trabalhadores nos corredores da VISA, convidados a expor as histórias que contemplavam o cotidiano laboral a partir da colaboração de um contador de histórias em uma oficina denominada "Histórias da VISA Real". Essa primeira técnica referiu-se ao processo de comunicação interno da área de VISA, considerando sua fragmentação e modo de transmissão de informações verticalizado, centrado no emissor da mensagem. 0 que requereu estratégias de comunicação específicas e propiciadoras de reflexão, bem como a formação de vínculos entre a equipe de trabalho, baseando-se no referencial da educação crítica e libertadora, de construção de saber a partir da polifonia (Freire ${ }^{13}$ ).

O propósito da oficina foi socializar as experiências vividas pelos diversos atores pertencentes à VISA e compartilhar as múltiplas dimensões do trabalho, conhecer as percepções dos trabalhadores sobre o cotidiano e suas práticas empreendidas, e refletir acerca do processo de trabalho por meio das narrativas construídas coletivamente, reconhecendo a consideração do risco como fenômeno social complexo. Procurava-se, então, resgatar um diálogo que ampliasse e integrasse as práticas e ao mesmo tempo respeitasse a história à qual os trabalhadores já estão inseridos e que, certamente, irá sucedê-lo.

A oficina, com um formato aparentemente lúdico, evidenciou situações angustiantes, tensões ocupacionais e deficiências no modo de fazer vigilância, constituindo um conjunto de sinais para mudanças que se faziam necessárias. Contribuiu para a formação de vínculos e construção dialógica de propostas de trabalho, com ênfase na co-responsabilização. As situações narradas continham aspectos cômicos e dramáticos sempre reveladores de contextos so- cioeconômicos, políticos, culturais e subjetivos, permeados por relações de saber e poder. Aproximando-se da concepção de Oliveira12, que caracteriza 0 ato de contar e ouvir histórias como um ato de troca, bem como de assumir uma postura crítica e reflexiva. Contar histórias propicia desvendar conflitos e impossibilidades, além de transformá-los em soluções ou possibilidades.

A prática utilizada de contar histórias é considerada desde tempos antigos por todas as culturas. Segundo Meneghel ${ }^{14}$, as narrativas constroem a realidade dos sujeitos que constroem a vida em sociedade, contribuindo para 0 enfrentamento dos mecanismos de exploração/dominação. As experiências intersubjetivas adquiridas no cotidiano das ações em VISA mediante as relações com setores regulados e cidadãos podem, pois, ser reveladoras de uma interação significativa capaz de contribuir para o aprimoramento técnico dos trabalhadores, para a reflexão sobre o processo de trabalho desenvolvido e para o empoderamento dos sujeitos comprometidos na ação.

Cabe ressaltar que a inserção da arte de contar histórias estabeleceu uma dinâmica que publicizava a realidade do processo de trabalho em VISA, explicitando os problemas, e simultaneamente procurava meios para resolvê-los. Situação que tornava os suj eitos contadores no que Deleuze ${ }^{15}$ denomina de aprendiz-artista, aquele "capaz de reinventar-se permanentemente". A arte se configura como uma ferramenta que induz à aprendizagem. A partir da concepção desse filósofo francês, consideramos que um artista genuíno nunca perde a sua condição de aprendiz, sendo capaz de sustentar a intenção do grupo de pesquisadores de manter as "Histórias da VISA Real" como uma ferramenta permanente de aprimoramento para o processo de trabalho em VISA.

\section{Entre o sussurro e a voz da Vigilância Sanitária}

A segunda tecnologia que emergiu durante as vivências da pesquisa foi o Seminário Vigilância Sanitária, Integralidade e Mobilização Social, realizado nos dias 26 e 27/06/2008. 0 evento contou com 350 participantes da comunidade, representantes da VISA dos três níveis de gestão, Ministério Público, dos setores regulados, de outras secretarias do município, do Conselho Municipal de Saúde e da comunidade organizada, além de outros técnicos da área de saúde e estudantes. As ferramentas adotadas para a interlocução com os participantes do evento foram apresentação teatral, mesa redonda e grupos de discussão temática. Teve como conferência de abertura "Vigilância Sanitária: Responsabilidade Pública na Promoção da Saúde". O Seminário teve o objetivo de promover o debate público sobre VISA e fortalecer parcerias institucionais a partir de informações pertinentes ao PDVISA. A necessidade de realização desse evento surgiu devido a uma intercorrência relacionada a um estabelecimento inspecionado e interditado. A ação da vigilância, embora respaldada pela legislação e pelo entendimento da Promotoria Pública, foi considerada arbitrá- 
ria pelo poder político local, o que motivou a direção a discutir com os técnicos as ações realizadas.

Cientes da possibilidade de exacerbação desse tipo de particularismo em um ano de eleições municipais, essa situação provocou certa desmobilização no grupo de técnicos. Era comum no departamento de VISA ouvir frases do tipo "em ano político a VISA não pode fazer nada". Consideração que se apropriava da constatação de que em anos anteriores evidenciava-se o predomínio de interesses particularistas em relação às necessidades da população. Esse estado de coisas poderia fortalecer a condição de imobilismo, a supremacia do poder, o menosprezo ao saber técnico e às exigências de controle sanitário.

Na busca de minimizar esse tipo de interferência no processo de trabalho em VISA, pensou-se a possibilidade de realização de um seminário, de maneira a divulgar seus objetivos, missão e complexidades, a fim de que se estabeleça a mobilização de agentes sociais para uma nova cultura de saúde.

Dessa forma, procurou-se trazer à luz algo às vezes desconhecido ou pouco conhecido na perspectiva dos diversos atores sociais envolvidos, objetivando aproximá-los do que é dever e direito dentro da perspectiva de cidadania. Conforme explicitado pela gestora em Vigilância Sanitária do município em seu discurso de abertura do Seminário, data em que se comemoravam os cem anos de nascimento de Guimarães Rosa:

"Se os sertões de Guimarães Rosa retrataram há mais de cinquenta anos esses territórios onde não se identificam as qualidades de cidadania, e hoje, contemporâneos, 'onde viver é muito perigoso', onde somos urbanizados e globalizados, de quantos sertões ainda são feitas as cidades?" (Daniella Guimarães de Araújo - 2008).

O compromisso de diminuir "esses sertões" e ampliar a socialização do conhecimento em VISA parecia estar associado à consolidação de redes sociais para garantir os princípios que regem a questão cidadania, além de exigir um espaço de discussão com a participação dos múltiplos atores envolvidos que, também, contemplasse os problemas pertinentes ao campo da saúde que afetavam a cidade.

A importância de espaços que privilegiem as relações sociais como esse são enfatizados por Andrade e Vaitsman ${ }^{16} \mathrm{e}$ Shererer-Warren ${ }^{17}$ como elementos que fundamentam a participação social. As autoras afirmam que a formação de redes de apoio se sustenta na democratização da informação e na conscientização quanto aos direitos e à defesa dos próprios interesses. Pois as redes aproximam os distintos atores sociais, viabilizam o diálogo entre diferentes interesses e valores, representando não mais um suj eito, mas um coletivo. 0 que ficou evidente na pró-atividade da equipe de trabalhadores na organização do evento.

Andrade e Vaitsman ${ }^{16}$ assinalam que as relações sociais se orientam por "trocas", onde a atenção dispensada é "retribuída na mesma intensidade". Estimulando o aumento da confiança pessoal, satisfação com a vida e capacidade de enfrentar problemas, gerando uma sensação de coerência e controle da vida. O Seminário se constituiu como o lugar de construção de conhecimento/saber e de reconhecimento/poder no que concerne ao objeto VISA em suas várias dimensões, a partir dos diferentes olhares que se revestiram de um poder transformador de solidariedade e co-responsabilização em relação à condição de vida.

0 evento contou com 350 participantes da comunidade, representantes da VISA dos três níveis de gestão, Ministério Público, dos setores regulados, de outras secretarias do município, do Conselho Municipal de Saúde e da comunidade organizada, além de outros técnicos da área de saúde e estudantes. As ferramentas adotadas para a interlocução com os participantes do evento foram apresentação teatral, mesa redonda e grupos de discussão temática. Teve como conferência de abertura "Vigilância Sanitária: Responsabilidade Pública na Promoção da Saúde".

Em um segundo momento, em uma mesa trabalhou-se a questão da modernidade e suas perspectivas para a VISA no âmbito local, incluindo algumas das estratégias utilizadas, como a mobilização da sociedade para transformar consumidores em cidadãos e a integração vigilância sanitária e seus múltiplos parceiros para promover saúde.

E, em um terceiro momento, visando privilegiar a escuta dos diversos participantes, estruturaram-se dez grupos temáticos centralizados em três temas centrais, subdivididos em dez subtemas. 0 primeiro tema se referiu à Vigilância Sanitária de produtos, serviços e ambientes: ações de fiscalização e monitoramento na cidade, este com quatro subtemas: a qualificação do processo de trabalho do setor regulado; 0 reconhecimento e inclusão social do mercado informal; a efetivação da intersetorialidade e a fiscalização referenciada pela dimensão da situação de risco à saúde. 0 segundo tema proposto foi Integralidade das ações: articulações para dar respostas aos problemas de saúde. Ele foi composto pelos seguintes subtemas: modelo tradicional de vigilância $\mathrm{x}$ nova proposta (PDVISA); organização do processo de trabalho em vigilância sanitária e demais vigilâncias e mapeamento de situações de risco: possibilidades e impossibilidades. Enquanto o terceiro tema contemplou a questão da Mobilização e Comunicação Social: contribuição para a construção de uma cultura de saúde, tendo como subtemas a mobilização social: identificação e responsabilização de atores sociais; o processo de mobilização e comunicação social e o desafio da formação de um comitê de mobilização social para a multiplicação das ações.

A inserção nos grupos se fez com a livre escolha de cada participante. A partir das discussões temáticas originadas nesses grupos elaborou-se a "Carta de Sete Lagoas" como produto das intenções do Seminário. Para efeito de avaliação do Seminário e como fonte de dados para a pesquisa, utilizou-se como técnica de coleta de dados a observação participante, aplicação de questionários semiestruturados e a análise da carta. Os dados foram analisados empregando a técnica da Hermenêutica Dialética, com base em Minayo ${ }^{18}$.

Observou-se que as avaliações referentes ao Seminário foram favoráveis. Evidenciou-se a importância do debate público para se tomarem decisões que possam afetar as condições de vida e saúde da coletividade, atraindo sujeitos que 
as entendem como uma questão de responsabilidade pública. Diante das produções originárias dos grupos de discussão temática observou-se que o estabelecimento de mecanismos como esse para a escuta da sociedade constitui uma maneira de privilegiar atividades voltadas à educação para a saúde, democratizar a informação e ampliar a consciência sanitária. A complexidade das ações em VISA foi sinalizada como determinante para que a sua gestão seja baseada em princípios como a intersetorialidade, multiprofissionalidade, interdisciplinaridade e de co-responsabilização, demarcando o compromisso de fortalecimento do SUS.

Nessa perspectiva, o seminário constituiu-se como uma forma de nortear e viabilizar ações estratégicas, consolidar a ação técnica da VISA e simultaneamente sua natureza política. Cumprindo seus pressupostos de um agir comunicativo, de direcionar a continuidade do planejamento e de contribuir para a "integralidade possível", conforme afirma Cecílio ${ }^{19}$.

Costa e Rangel ${ }^{20}$ também sinalizam a fundamentalidade sobre uma rede ampliada de conversações fora dos muros dos serviços para a ausculta aos discursos sociais. Nessa perspectiva, o seminário alcançou seu propósito de agregar conceitos, análises e proposições capazes de contribuir para o enfrentamento da situação de saúde, e nesse caso especifico com questões de VISA. Além disso, reforçou o empoderamento dos sujeitos envolvidos e criou uma visibilidade desejada para a área, principalmente, em um município tão marcado por sua fragmentação no campo da saúde, constantes trocas de gestores do SUS e pelo sussurro da Vigilância Sanitária.

Dessa maneira, enquanto processo resultante de uma pesquisa ação em desenvolvimento, baseada no princípio da co-responsabilização, em um ano eleitoral, o seminário constituiu-se como um produto de pesquisa e, ao mesmo tempo, uma ferramenta que estimula a abertura de um campo de possibilidades de ações com os diversos atores estratégicos. Representou, assim, a convocação das forças sociais, através de mecanismos de concentração e negociação entre os setores sociais e institucionais, na qual os propósitos se instituem à frente dos interesses econômicos.

\section{Os cidadãos que visam mais}

A formulação do Proj eto VISAMAIS ocorreu junto com a elaboração do Plano de Ação 2008 e sua implementação veio em sequência ao Seminário. Sua origem se deu a partir de uma ideia do grupo de técnicos de realizar uma experiência de mobilização em nome de uma nova cultura em saúde. E baseou-se no eixo cinco do PDVISA, Construção da Consciência Sanitária, Participação e Mobilização Social. Nessa perspectiva, a equipe responsável, com o apoio e participação da gestão, buscou contribuir para formação de cidadãos co-responsáveis pela melhoria das condições de vida de suas comunidades.

Essa proposição tomou corpo e se direcionou à qualificar multiplicadores que contribuíram para a disseminação de informações, além de viabilizar espaços de discussão acerca da VISA. Optou-se por trabalhar com dois diferentes públicos, como os alunos de uma escola estadual em área social com significativa vulnerabilidade e com um grupo de escoteiros.

Partindo de uma postura dialógica, centrada nas próprias representações das diferentes comunidades, foram realizadas reuniões para discutir a VISA e seus eixos de atuação. E, principalmente, conhecer o desejo da participação voluntária dos jovens selecionados como multiplicadores. Foram qualificados 80 jovens para serem os re-editores desses novos conhecimentos em suas comunidades.

No primeiro encontro, procurou-se apreender as imagens, ideias e percepções desses j ovens em relação à vigilância sanitária, a partir das suas falas. Utilizou-se como técnica de análise de dados a Hermenêutica Dialética, com base em Minayo ${ }^{18}$, que favoreceu a problematização quanto ao papel da vigilância sanitária, possibilitando a interpretação e constituindo novas discursividades em relação à VISA. Cada público revelou suas singularidades na concepção de vigilância e perspectivas de colaboração. A vigilância para a maioria dos adolescentes está associada a uma concepção higienista - "Quando penso em vigilância sanitária eu penso em higiene em geral" - "Vigilância sanitária é uma coisa em que as pessoas fiscalizam as casas para não haver doença" - "Vigilância sanitária é para mim o que fazem para combaterem as bactérias, doenças e outras coisas nesse sentido...". Outros a reconhecem como: “...é uma organização que é chamada ANVISA; essa organização ajuda as pessoas nas dificuldades ou no direito do cidadão."

Um dos adolescentes apesar de uma visão também higienista já possuía uma acepção mais avançada, demarcando assim a sua ação preventiva: “( ...) é uma empresa que fiscaliza os bares, restaurantes, cabeleireiros para olhar se está limpo, é um departamento que cuida da prevenção de riscos à saúde da população".

A partir da acolhida inicial os adolescentes foram convidados a descobrir junto com os técnicos do proj eto o vasto conjunto de ações pertinentes à VISA e as necessárias parcerias para se produzir uma co-responsabilidade solidária. Nesse período, outro grupo foi convidado a participar e inserir-se no Projeto VISAMAIS, os adolescentes do PROJ OVEM, projeto federal socioeducativo formado principalmente por jovens advindos do bolsa família. A preocupação de alguns adolescentes desse grupo foi sintetizada na seguinte abordagem: "Doutora, será que depois dessa parceria com a VISA... dessa capacitação... eu arranjo trabalho?". A pergunta surpreendeu os técnicos, que se defrontaram com uma necessidade mais concreta, que não poderia ser negligenciada. No entanto, entenderam que essa inquietação fugia da governabilidade deles ou mesmo da VISA.

Alguns recursos foram utilizados para a aceitação e avanço das discussões. Entre eles, uma linguagem diferenciada, problematização de experiências vivenciadas e o uso de filmes, a partir dos quais viabilizou-se o conhecimento das realidades vigentes em algumas das comunidades. Estratégia que significou para a equipe um rico processo de aprendizado e colaboração, pois o senso comum passou a ser reconhecido como importante para a formação de uma nova cultura em saúde. A formação 
desse tipo de rede colaborativa possibilitou maior visibilidade da VISA para a população e demais instituições públicas.

Na sequência das ações surge durante as reuniões de capacitação o desejo de receber no município a Mostra Cultural realizada pela FIOCRUZ denominada VISA e Cidadania, bem como o de incluir os jovens como monitores da Mostra. Depois de várias articulações foi possível trazer a mostra. A equipe da FIOCRUZ realizou uma qualificação específica para os monitores.

Os resultados do VISAMAIS, além de beneficiarem os jovens formadores de opinião, tiveram o potencial de despertar os demais técnicos para um novo processo de trabalho e de mostrar a VISA além de suas práticas fiscalizatórias. Assim, constitui-se mais uma perspectiva de trabalho com mobilização, que segundo Andrade e Vaitsman ${ }^{16}$ e Shererer-Warren ${ }^{17}$ são essenciais para a construção de redes sociais, visando garantir a cidadania e a expansão da legitimidade da VISA no município em questão.

A avaliação dos jovens em relação ao projeto foi positiva e ficou explícito o desejo de dar continuidade ao desenvolvimento da proposta, pois "Adoraria continuar contribuindo...". A mudança de atitude foi enfatizada a partir de colocações como "Tenho sido crítica ao chegar em qualquer estabelecimento ou ao preparar alimentos em casa" e "Com isso aprendi que o papel da VISA é parte da vida de cada pessoa (...)". A primeira demonstra o reconhecimento de que as noções trabalhadas pela vigilância em ambientes como farmácias, restaurantes, padarias, comércios, consultórios, hospitais, entre outros, devem também estar presentes nas ações domésticas. Portanto, deixa de ter uma ação exclusivamente policialesca em relação ao outro e insere-se em uma concepção que é a responsabilidade de cada um e deve estar presente nas ações cotidianas.

\section{Desvelar: A Vigilância Sanitária se mostra na Mostra}

Como já assinalado, uma das ações do VISAMAIS foi a recepção da Mostra Cultural VISA e Cidadania no município em outubro de 2008, concebida pelo Centro Colaborador de VISA da FIOCRUZ - CECOVISA/ FIOCRUZ. A estratégia de receber essa mostra surgiu no bojo dos debates com os integrantes do VISAMAIS. Essa mostra situou-se como estratégia culturalmente sensível para favorecer a aproximação da área de vigilância com a sociedade. Disponibilizando mais uma vez um espaço de discussão sobre os benefícios de uma VISA qualificada em uma cultura de saúde, bem como buscar contemplar os eixos 3,4 e 5 do PDVISA que se referem à Vigilância Sanitária no contexto da atenção integral à saúde: Produção do conhecimento, pesquisa e desenvolvimento tecnológico, e Construção da consciência sanitária: mobilização, participação e controle social, respectivamente.

Essa ação exigiu compromissos e compartilhamento de responsabilidades, além de uma negociação de 60 dias, e constituiu-se pouco tempo após o seminário. E, por ser a primeira vez que a mostra viria ao Estado de Minas Gerais, estaria contemplando o acesso de outros municípios da região de Sete Lagoas.
Em uma discussão inicial com a equipe da VISA, Comunicação Social, secretários municipais de Saúde e de Educação agendou-se o curso Cidadão Informado: A saúde agradece. Os secretários assumiram a responsabilidade de convocar a equipe da atenção básica e diretores de escolas municipais para a apresentação da Mostra Virtual e convidá-los para a participação no curso.

O curso foi ministrado no auditório da VISA por uma docente do CECOVISA/ENSP. Os participantes eram pertencentes ao VISAMAIS, Programa Saúde da Família, Vigilância Sanitária, educadores de escolas particulares, públicas estaduais e municipais, escolas técnicas, SENAC, do município e região. Foram capacitados 300 profissionais para serem potenciais multiplicadores dos conhecimentos. 0 aproveitamento e a participação no curso foram significativos e as avaliações consideradas positivas.

Essa capacitação prévia e a visitação à Mostra propiciaram amplo debate sobre a missão da VISA e seus benefícios para a coletividade em um município onde ela não era considerada em sua amplitude. Toda a equipe da VISA e do Proj eto VISAMAIS foi incluída na monitoria da mostra. Consequentemente, uma importante parte da comunidade local passou a reconhecer a VISA como integrante do SUS. Esses benefícios, aliados ao benefício da inclusão social de adolescentes no processo de construção de cidadania, demonstram que as ações educativas e comunicativas contribuem significativamente para a visibilidade da VISA, que passa a ter a sua ação associada à defesa da saúde e promotora de qualidade de vida, além do significado punitivo e fiscalizatório socialmente construído.

Ouvir a população foi um modo de instaurar um processo de educação sanitária diferenciado, não mais representando um acúmulo de fragmentos científicos espalhados por meio de folders, cartilhas e palestras. Buscava-se a dimensão subjetiva, a descoberta do que fazia sentido acerca da temática da VISA.

Esse espaço se constituiu como uma possibilidade de expandir um estreitamento das relações entre VISA e sociedade, aproximando da concepção de Costa ${ }^{21}$ de que as estratégias utilizadas pela VISA para o controle dos riscos devem reconhecer e dialogar com aquelas produzidas no âmbito da sociedade.

Estiveram presentes representações de diversas instituições locais, conselheiros e agentes comunitários de saúde, coordenações da atenção à saúde, representantes da Gerência Regional de Saúde, da Superintendência Estadual de VISA, Superintendência de Pesquisa da ESP-MG, CECOVISA/NESCON, consultores e colaboradores, técnicos da VISA da região. As escolas municipais e estaduais foram as mais constantes nesse período de 20 dias da Mostra Cultural, com a presença de mais de 2.500 visitantes. Alguns municípios da região também estiveram presentes.

Entre os pontos positivos, visualizou-se o entusiasmo dos visitantes, a responsabilização da equipe de VISA local, o envolvimento dos monitores, principalmente do grupo de escoteiros da cidade. Este grupo destacou-se como parceiro das ações e potencial colaborador como formador de opinião na perspectiva de construção de cidadania. 
Como ponto negativo destaca-se a semana de recesso escolar durante o período de visitação, ocorrido durante as comemorações da semana da criança e do mestre; as deficiências no processo de comunicação e consequente fragilização da mobilização social após as eleições municipais.

A Mostra Cultural VISA e Cidadania cumpriu o objetivo de aproximar a população da Vigilância Sanitária e disseminar conhecimentos acerca dos riscos à saúde, bem como os obj etivos do Proj eto VISAMAIS, planejado para esse exercício, com o intuito de expandir as ações de vigilância para os diversos públicos, visando à multiplicação dos atores envolvidos na proteção e promoção da saúde.

0 trabalho realizado previamente com os candidatos a monitores da mostra foi essencial para a adesão ao projeto e o envolvimento deles. Esses, na perspectiva deste projeto, capacitaram-se também como re-editores para que em sua linguagem própria revelassem os conhecimentos apreendidos para suas comunidades. Nesse sentido, a Mostra foi a culminância das ações pedagógicas.

\section{Dos Contos à Mostra Cultural: uma breve síntese}

A oficina de contar histórias trouxe à tona questões relacionadas à vulnerabilidade dos trabalhadores da VISA, ao adoecimento desses diante das pressões cotidianas, das dificuldades de rompimento com uma rotina carregada de significações construídas no decorrer do tempo. Mas, também, evidenciou como a população e os setores regulados encaram a própria missão da VISA, muitas vezes permeado pelo desconhecimento de suas reais atribuições na defesa da saúde. Das dez histórias escritas, sete versavam sobre esse tema.

o compartilhamento das experiências promoveu uma aproximação entre a equipe e fomentou a credibilidade do grupo em relação aos processos criativos, à autonomia relativa às ideias que poderiam ser geradas e renovadas em um cotidiano aberto à inventividade. As discussões das histórias narradas continham em si os problemas e as origens das experiências e o vislumbre das mudanças necessárias. E puderam ser utilizadas como ferramentas na reflexão crítica sobre os processos vivenciados.

A participação numericamente expressiva no Seminário e a diversidade de atores traduziram a VISA como área imprescindível ao SUS. Tornou visível a anterior obscuridade de um departamento, subjugado pela conformidade de sua condição. Revelou o fortalecimento da gestão participativa e suas implicações na co-responsabilização da equipe. A carta de intenções elaborada contou com a participação dos diversos atores e cumpriu a sua função de contribuir para a mudança de posturas sobre o fazer em um ano político. Fez acreditar que é possível mobilizar pessoas para a temática da VISA e mostrou por quais estratégias. Demonstrou que a integralidade é uma via difícil, entretanto, possível.

0 projeto VISAMAIS ao pretender socializar a VISA mostrou que os resultados, além de beneficiarem os jovens for- madores de opinião em sua capacitação reflexiva e crítica sobre os produtos, serviços e ambientes, tiveram o potencial de despertar os demais técnicos para um novo processo de trabalho, condição essencial para tornar atitude a construção de cidadania e expandir a legitimidade da VISA no município em questão.

Mostrou que é possível uma aproximação acolhedora com a comunidade demarcando a possibilidade das pontes e a formação dos vínculos sob a orientação dos diálogos. Assinalou que é possível contar com redes de apoio na reedição dos conhecimentos. E apontou que muitos esperam da VISA ações educativas, além de coerções e punições.

A Mostra Cultural consolidou as afirmações anteriores, trazendo mais participação e mais histórias pra contar. Visibilidades e fortalecimentos além da opacidade e menos valia. Trouxe a atenção básica para perto e seus potenciais colaborativos em relação ao controle dos riscos. A VISA, definitivamente, não se encontrava mais no limbo nem tampouco se situava como órgão apenas de fiscalização. A mostra reafirmou o campo notório da VISA na comunicação social, seu vasto compromisso com a formação de uma cultura de saúde e com o despertar de uma "posição cidadã".

No trânsito pelas quatro tecnologias despontadas pode-se afirmar que a acolhida foi favorável e reveladora de novos caminhos e criações, instaurando na equipe um espaço dinâmico para expressão e cooperação.

\section{Considerações finais}

Ficou evidente a possibilidade que a modalidade de pesquisa-ação criou para um melhor conhecimento do contexto social em VISA, bem como método favorecedor de espaços de reflexão e ação coletiva para a transformação da sua realidade. A sua flexibilidade viabilizou a adoção de técnicas pouco usuais tanto no campo da vigilância como no da pesquisa, propiciando uma abordagem mais interativa com o complexo contexto em VISA.

À luz das quatro tecnologias apresentadas pode-se vivenciar a fundamentalidade da participação social, o reconhecimento da importância do envolvimento e da responsabilização dos diversos suj eitos no cuidado em saúde e da VISA como constitutiva do campo da saúde.

Partindo das histórias que revelaram o desconhecimento da população sobre a vigilância sanitária e a fragilidade inerente à complexidade de seus obj etos de cuidado, um percurso criativo foi emergindo de um conjunto de sujeitos que nomearam suas ações e transformaram uma realidade antes centrada na mobilidade das inspeções sanitárias e na imobilidade de seus diagnósticos.

0 acréscimo das quatro tecnologias viabilizou espaços de crítica e reflexão sobre concepções, práticas e acordos vividos e ampliou a capacidade de respostas aos problemas de saúde a partir das múltiplas vozes que compõem a vigilância sanitária, principalmente no que se refere aos municípios. 


\section{REFERÊNCIAS}

1. Costa EA. Vigilância Sanitária: proteção e promoção da saúde. São Paulo: Hucitec/ Sobravime; 1999.

2. Lucchese G. Globalização e regulação sanitária: os rumos da vigilância sanitária no Brasil [tese]. Rio de J aneiro: Escola Nacional de Saúde Pública/ Fiocruz; 2001.

3. Agência Nacional de Vigilância Sanitária (Brasil). Plano Diretor de Vigilância Sanitária. Brasília: ANVISA; 2007.

4. Brasil. Portaria $\mathrm{n} 01052$, de 8 de maio de 2007. Aprova e divulga o Plano Diretor de Vigilância Sanitária. Diário Oficial da União. 09 maio 2007; Seção 1, p. 33.

5. Merhy EE. Em busca do tempo perdido - a micropolítica do trabalho vivo em saúde. In: Merhy E E, Onocko R. Agir em saúde. São Paulo: Hucitec; 1997. cap. 2. p.71-112.

6. Thiollent M. Metodologia da pesquisa ação. 14. ed. São Paulo: Cortez; 2005. 132 p. Pósfacio. 1985.

7. Thiollent M. Pesquisa Ação nas Organizações. São Paulo: Atlas, 1997. 164p.

8. Richardson RJ. Como fazer pesquisa ação?Textos Online [internet] [acesso em 14 nov. 2008]. Disponível em: http:// www.ic.ufmt.br:8080/c/ document_library/get_file?p_I_id $=12683 \&$ folderld $=53266 \&$ name $=$ DLFE-2406. pdf

9. Franco MAS. Pedagogia da Pesquisa-ação. Educ. Pesqui. [internet]. 2005 [acesso em 22 set. 2006];31(3):483-502. Disponível em: http:// www.scielo.br/ pdf/ep/v31n3/ a11v31n3.pdf

10. Matus C. Política, planejamento \& governo. Brasília: IPEA; 1997.

Data de recebimento: 06/06/2013

Data de aceite: $26 / 08 / 2013$
11. Bakhtin MM. Marxismo e filosofia da linguagem: problemas fundamentais do metodo sociologico na ciencia da linguagem. São Paulo: Hucitec, 1979. 182 p.

12. Oliveira MAO. Ouvir e contar histórias. Imaginário. 2005;11(11);239-246.

13. Freire P. Pedagogia da autonomia: saberes necessários à prática educativa. 2. ed. São Paulo: Paz e Terra; 1996. $165 \mathrm{p}$.

14. Meneghel SN, Iñiguez L. Contadores de histórias: práticas discursivas e violência de gênero. Cad Saude Publica. 2007; 23(8): 1815-1824.

15. Deleuze G. Proust e os signos. 8. ed. Rio de Janeiro: Forense; 1987. $183 \mathrm{p}$.

16. Andrade GRB, Vaitsman J. Apoio social e redes: conectando solidariedade e saúde. Cien Saude Colet. 2002; 7(4): 925-934.

17. Shererer-Warren Ilse. Das mobilizações às redes de movimentos sociais. Soc. estado. 2006;21(1):109-130.

18. Minayo MCS. O desafio do conhecimento: pesquisa qualitativa em saúde. 10. ed. São Paulo: Hucitec; 2007. 406 p.

19. Cecílio LCO. Os sentidos da integralidade na atenção e no cuidado à saúde. Rio de Janeiro: IMS/ UERJ; 2006. p. 113-126.

20. Costa EA, Rangel ML, organizadores. Comunicação em Vigilância Sanitária: princípios e diretrizes para uma política. Salvador: EDUFBA; 2007.

21. Costa EA. Fundamentos da vigilância sanitária. In: Costa $E$ A. (org.) Vigilância Sanitária: temas para debate. Salvador: EDUFBA; 2009. 